\title{
Personalized diabetes management: what do patients with diabetes mellitus prefer? A discrete choice experiment
}

\author{
Axel C. Mühlbacher ${ }^{1,2,3}$ (D) Andrew Sadler ${ }^{1} \cdot$ Christin Juhnke $^{1}$
}

Received: 18 September 2018 / Accepted: 13 January 2021 / Published online: 15 February 2021

(c) The Author(s) 2021

\begin{abstract}
Background There are unresolved procedural and medical problems in the care of diabetes, which cause high costs for health systems. These include the inadequate glycemic adjustment, care gaps, therapeutic inertia, and a lack of motivation. Personalized diabetes management can be seen as a kind of "standard process" that provides both physicians and patients with a framework. The aim of this empirical survey is the evaluation of patient preferences regarding personalized diabetes management. The purpose of this experiment is to demonstrate the properties of the programs that are relevant for the choice of insulin-based therapy regimens for patients with type II diabetes mellitus.

Methods A discrete choice experiment (DCE) was applied to identify preferences for a personalized diabetes management in patients with type II diabetes mellitus. Six attributes were included. The DCE was conducted in June 2017 using a fractional factorial design, and the statistical data analysis used random effect logit models.

Results $N=227$ patients $(66.1 \%$ male) were included. The preference analysis showed dominance for the attribute "occurrence of severe hypoglycemias per year" [level difference (LD) 2765]. Preference analysis also showed that participants weight the "risk of myocardial infarction (over 10 years)" (LD 1.854) highest among the side effects. Within the effectiveness criterion of "change in the long-term blood glucose level (HbA1c)" a change at an initial value of 9.5\% (LD 1.146) is weighted slightly higher than changes at 7.5\% (LD 1.141). Within the random parameter logit estimation, all coefficients proved to be significantly different from zero at the level $p \leq 0.01$. The latent class analysis shows three heterogeneous classes, each showing clearly different weights of the therapeutic properties. This results in a clear three-folding: for 1/3 of the respondents the change of the long-term blood sugar ( $\mathrm{HbA} 1 \mathrm{c}$ value) is the top objective. Another third is solely interested in the short-term effectiveness of the therapy in the sense of the occurrence of severe hypoglycemias per year. The last third of the interviewees finally focuses on the follow-up regarding cardiovascular events. Overall, there were five structural and personality traits which have an influence on the respective probability of the class membership.

Discussion/conclusion This study identifies and weights the key decision-making criteria for optimal management of diabetes from the perspective of patients. It was shown that the effectiveness of a care program is the most important from the perspective of the patient and avoiding severe a hypoglycemia has the greatest influence on the choice. The risk of myocardial infarction as a follow-up disease and the long-term adjustment of the blood glucose follow the importance. In the analysis of possible subgroup differences by means of latent class analysis, it was found that three preference patterns exist within the sample. The generated preference data can be used for the design of personalized management approaches. It remains open to the extent to which expert opinions and patient preferences diverge.
\end{abstract}

Keywords Type II diabetes mellitus · Personalized diabetes management $\cdot$ Discrete choice experiment $\cdot$ Latent class analysis

JEL Classification I12 Health Behavior · C35 Discrete Regression and Qualitative Choice Models · Discrete Regressors · Proportions $\cdot$ C44 Operations Research $\cdot$ Statistical Decision Theory

Axel C. Mühlbacher

muehlbacher@hs-nb.de

Extended author information available on the last page of the article 


\section{Decision-making context: diabetes mellitus type II and personalized diabetes management}

\section{Diabetes mellitus}

Diabetes mellitus is one of the most elaborate and expensive widespread diseases in Germany [1]. The high socioeconomic importance of diabetes is the result of severe complications, reduced life expectancy and reduced ability to work as well as the necessary comprehensive medical care for the patients [2].

It is estimated that about $8-10$ million people are currently suffering from this incurable disease in the Federal Republic of Germany [3]. It is estimated that about twice as many people will be affected by diabetes by 2020 [4, 5]. The International Diabetes Federation estimates that by 2030 the worldwide number of people with diabetes will have increased from currently 285 million by more than $50 \%$ to about 438 million [6].

Diabetes mellitus is a glucose metabolism disorder that is characterized by chronic hyperglycemia [7]. A variable combination of impaired insulin secretion and/or reduced insulin resistance results in type II diabetes [8, 9]. This is the most common form of diabetes, which is diagnosed in about $90 \%$ of diabetic patients and is mostly only manifested in adulthood. This type of diabetes is characterized by a decreased insulin effect and a reduction in the insulin distribution and occurs more and more frequently also in younger people. Reasons for this are factors such as overweight, lack of exercise and incorrect diet, which significantly increases the risk of developing diabetes.

Studies have shown that diabetics have a lower quality of life than non-diabetics-especially patients with diabetes-related complications, as there is a risk of blindness, dialysis, or amputation of limbs. Likewise, the disease often causes emotional stresses-mental disorders such as depression occur twice as frequently in diabetics than in the normal population $[8,10,11]$. Hence, co-morbidities and secondary diseases of diabetes can lead to a reduction in the quality of life and a shortened life.

\section{Unresolved problems}

Diabetes mellitus is a major challenge for national health systems, both regarding the care processes and the associated expenditures. The changed lifestyle and demographic, social changes result in a high burden due to type II diabetes [12]. The care of patients with type II diabetes is performed on three levels: (1) about 80-90\% are under an outpatient care, (2) 10-20\% of patients are either permanently or temporarily dependent on an outpatient care unit, a diabetic specialist or a hospital outpatient clinic, as well as coordinating specialists (e.g. nephrologists, ophthalmologists, etc.) - especially when acute and/ or complications occur. An escalation of the treatment of acute and/or long-term complications necessitates parttime inpatient care (3) [13].

There are unresolved procedural and medical problem in the care of diabetes, which cause high costs for the health systems. These include in particular inadequate glycemic attitude, care gaps, therapeutic inertia as well as lack of motivation. The latter leads to a lack of therapy compliance and adherence of the patients and possible misunderstandings in the physician-patient communication [14].

The achievement of better therapeutic outcomes or the utilization of the therapeutic potential is often prevented by therapeutic inertia. Today, there are a variety of possibilities in differential therapy. However, these are not uniformly presented in recommendations for action and care guidelines for type II diabetes [15]. This often results in lengthy decision-making processes. The consecutive and consistent implementation of the therapeutic recommendations will be delayed. As a result, standards and an integrated care programs are required in diabetes care [15].

\section{Personalized diabetes management}

Despite all efforts to achieve the best possible diabetic therapy in Germany, an insufficient glycemic adjustment (HbA1c level $\geq 7.5 \%$ ) is found in almost half of the patients in type II diabetes [12]. A poor glycemic adjustment promotes the morbidity of patients with type II diabetes, especially the risk of developing micro- and macrovascular sequelae $[16,17]$.

Patients demand an individual/individualized therapy, even if the necessary motivation for (lasting) change in their lifestyles is missing at the same time. This not at least because doctors, as companions of the patients, can spend too little time and have little information about the patient's preferences [18].

Diabetes is a chronic disease that places high demands on the compliance and adherence of patients. The success of the therapy is determined by various factors such as compliance with the recommended blood glucose monitoring or the documentation of blood glucose profiles. The use of a personalized approach to diabetes management is discussed internationally and the success has been demonstrated in first studies. Studies show that Personalized Diabetes Management (PDM) can increase the effectiveness and efficacy of therapy and improve treatment outcomes [19-22].

The PDM can be understood as a kind of "standard process" that provides a framework for both physicians and patients. It stands for a personalized diabetes care tailored 
to the specific patient. Structured, therapy-adapted blood glucose self-monitoring is linked to electronic systematic analysis and graphical presentation, interpretation and communication of the patient's blood glucose measurements and diabetes data using a diabetes management software solution. This integrated therapy process is intended to enable improved quality of life, optimized therapy or optimized therapeutic outcomes (medical benefits) and economic added value. Personalized diabetes management thus has the task to realize an optimized diabetes care. Ultimately, the question of which tools and functionalities are used also depends on the needs and preferences expressed by the affected patients.

\section{Method, study design and decision-making model: how can preferences be measured?}

\section{Method of the discrete choice experiment (DCE)}

The discrete choice experiment (DCE) is a choice-based variant of the conjoint analysis, which became possible only through the theoretical work of Lancaster [23] and McFadden [24]. Instead of a ranking or evaluation of many different therapeutic features, a comparison of alternatives is made and a (choice) decision is made between different therapy options [25]. By means of the paired comparison, the degree of complexity of the task drops considerably for the patients, so that better data quality is to be expected [26-28]. The implementation of the discrete choice analysis also offers practical advantages due to its close proximity to reality. Hence, it has already emerged to one of the most frequently used preference measurement methods in health economic evaluation [29].

The structure of a discrete choice experiment and its analysis are multi-stage [26, 30-32]. The utility function is estimated by means of the maximum likelihood method. Depending on the underlying distribution function, different estimation methods (mostly probit or logit estimates) can be used [26, 29, 33-35].

\section{Literature review and AHP}

In a first step, a literature review (PubMed, Medline and Cochrane Library) was conducted on clinical aspects of insulin therapy in diabetes mellitus type II and its management. The aim of the search was to identify the potential properties and characteristics of these treatments, in general and from the patients' perspective. Based on the found full texts, a list of therapeutic and management features was created, discussed with experts and patient-relevant characteristics were tested in a preliminary Analytic Hierarchy Process with $N=202$ patients and $N=36$ experts (physicians, nutritionists, diabetes advisors, specialized diabetes nurses). The AHP included attributes on health-related quality of life as well as clinical aspects of diabetes care (outcomes, adverse events as well as co-morbidities).

\section{Attributes and levels}

Following the identification of the most important aspects of the treatment for type II diabetes mellitus and their possible manifestations through the literature research as well as the AHP, the DCE questionnaire was designed. Finally, the final decision model included six attributes (Fig. 1). The "change in the long-term blood glucose levels" has been described as a so-called "compound attribute" by two dimensions: the initial level and the change in percent.

These attributes were used as a basis for determining the importance of the features in the treatment of type II diabetes mellitus with personalized diabetes management and transferred into a standardized online questionnaire. Within the survey, all attributes included amateur-language descriptions. The description of the characteristics has been supplemented by a graphical representation. The objective was to simplify the decision by optimizing the presentation of the information.

\section{Data collection: experimental design, election scenarios and survey}

\section{Study population}

The empirical assessment of the patient's preferences was concentrated on insulin-treated patients with the indication diabetes mellitus type II. Patients' eligibility was linked to the following access criteria: age (18 years or older), diagnosis (diabetes mellitus type II), therapy (regular insulin administration), language skills (sufficient knowledge of German) and given informed consent.

The participants were recruited in cooperation with an external market research company. Data collection took place between 07.06.2017 and 17.06.2017.

According to the formula of Orme [36], at least $N=125$ subjects were necessary to estimate the main effects (with 12 choice tasks, 2 alternatives and a maximum of 6 variants). Since the current discussion indicates this value as the absolute lowest limit [37], a sample size of $N=400$ volunteers was applied to guarantee a statistically robust estimate and to carry out the analysis of subgroups.

\section{Legal requirements}

This study was an anonymous data collection. The Institutional Ethics committee of Hochschule Neubrandenburg has reviewed and approved the interviews and the survey. 


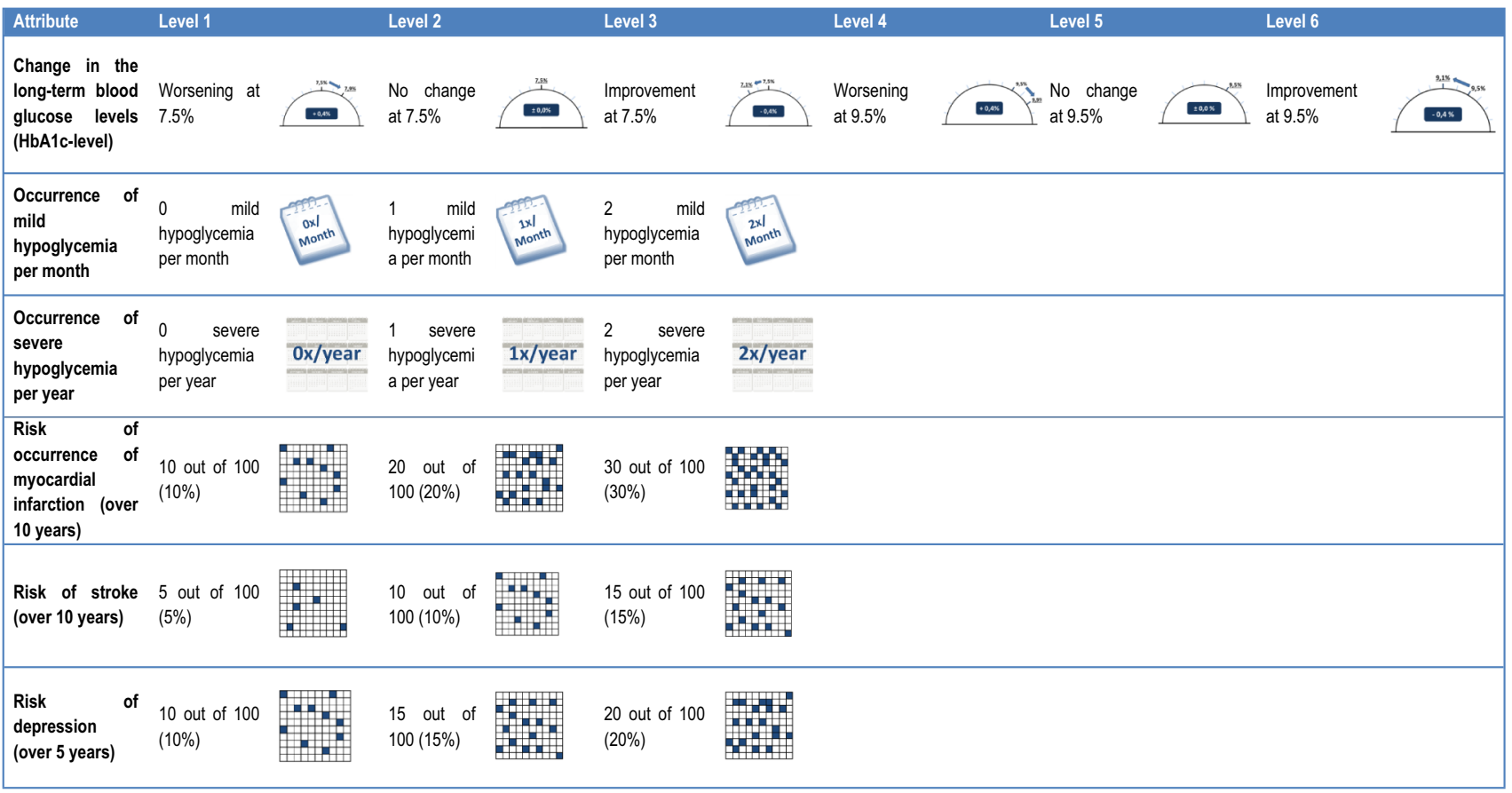

Fig. 1 Final decision model of the discrete choice experiments

All subjects submitted an informed consent prior to the first question of the survey and thus agreed to participate in the research project. All subjects were informed about the research project. The participating subjects were free to answer the questions addressed to them or to end the questionnaire at any time during the survey.

\section{Experimental design}

The software Ngene 1.2.0. [38] was used for optimal experimental design $(3 \times 5+6 \times 1$ design $)$. The chosen d-efficient design with zero prior estimates included 144 choices divided into 12 blocks, each with 12 choice tasks. The allocation of the participants to the individual blocks was randomized.

Based on the experimental design, two alternatives were displayed (binary choice sets). No status quo alternative was considered. Furthermore, there was no possibility for respondents to choose none of the presented alternative alternatives (None option). Respondents had to choose an alternative (forced choice).

\section{Data analysis}

The socio-demographic data collected in the first part of the questionnaire were analyzed using descriptive analyzes. The relative importance of each treatment attribute and level was estimated by means of multivariate methods (e.g. random parameter logit model, conditional logit model, latent class model) [39]. SPSS and STATA were used as analysis packages. In all analyzes, $p<0.05$ (double-sided) was assumed as statistically significant. The evaluation of the preference coefficients took place with consideration of the 95\% confidence interval. To explore the determining personality characteristics for class membership in the latent class analysis, cross tables and regression models (binary logistic and multinomial logistic regressions) were used to describe the class distribution by means of the significant structural parameters.

\section{Results: what do patients prefer?}

\section{Consistency tests to verify response quality}

The total respondent sample included $N=402$ patients. However, it is important to test the consistency of the responses to assess the reliability and validity of the responses. First, individual responses were examined to determine whether the principle of monotonous preferences was fulfilled. According to this, people always prefer more of every normal good [40, 41]. For this purpose, the first choice scenario was designed as a "dominant pair". Validity tests found that $N=36$ respondents failed to choose the better, dominant alternative.

For the "stability test", the first choice set was repeated at the end of the DCE. Respondents who did not select identical alternatives were also excluded $(N=111)$. The test re-test 
could indicate that the respondents had a learning effect and therefore answered the repeated question differently. However, a comparison of the models with and without application of the exclusion criteria showed a significant difference regarding model fit criteria (e.g. pseudo $R^{2}, \mathrm{AIC}, \mathrm{BIC}$ ) and magnitude of the coefficients (which affected the $z$-value and hence the $p$-value). The latter indicated that the excluded respondents were less confident in their choice decisions than the remaining respondents in the final model. Beyond, subsequent analysis showed a greater heterogeneity in the model with all respondents included in contrast to the reduced model. This also indicates that a considerable proportion of the respondents made arbitrary choice decisions.

In a further verification of the response validity, the sample was examined for respondents whose responses indicated that they were apparently not willing to trade between the characteristics. According to Marshall et al. [42] a respondent was classified as unwilling if he chose the same alternative in at least 10 of the 12 choice sets $(N=48)$. Finally, a repeated query on the current treatment of diabetes was used. Since treatment with regular insulin doses was an inclusion criterion for this study, respondents who indicated to be treated only with diet/exercise or only with oral antidiabetics during a repeated interrogation were also excluded $(N=12)$. Finally, $N=175$ respondents were excluded.

\section{Socio-demographic data}

Socio-demographic data of the final respondent sample of 227 patients is shown in Table 1 . Next to that, $56.4 \%$ were married, $62.9 \%$ were retired and $71.4 \%$ indicated their current health status to be excellent, very good or good. The average age was 56.6 years (SD 11.21). Regarding their diabetes type II diagnoses, $0.9 \%$ had received their diagnoses less than 6 month ago, 7.0\% between 6 and 24 months ago, $15.4 \%$ between 2 and 5 years ago and $23.3 \%$ between 5 and 10 years ago. $42.3 \%$ indicated that the diagnosis was made 10-20 years ago and for another $11.0 \%$ this was more than 20 years ago.

\section{Assumption of heterogeneity: random parameter logit}

In contrast to a conditional logit, the random parameter logit (also "mixed logit") takes unobserved heterogeneities between the survey participants into account.

Within the model calculation, effects coding was used $(-1,0,1$; reference category is the negative sum of the other two) and, therefore, no function was assumed about the attribute levels. With this coding, a coefficient is calculated for each level. The following table and figure illustrate the corresponding values.
In addition, the random parameter logit allows the assumption of heterogeneous responses within the sample. Since in the model calculation, all attributes were assumed to be random ("random parameter"), the extent of heterogeneous preferences can be derived via the respective standard deviations. The corresponding standard deviations are shown also in Table 2 (below). The graphical representation is shown in Fig. 2.

In this case, slight standard deviations in the graph indicate a rather homogeneous response behavior. This can be seen, for example, in "mild hypoglycemias". Here, there are only very small, mostly non-significant standard deviations in the coefficients. Another picture emerges from "risk of myocardial infarction". Here, the standard deviations in the coefficients for all levels are significantly different from zero, i.e. the preferences of respondents are very heterogeneous.

In the model calculation of the random parameter model, all attributes were assumed to be a "random parameter", i.e. the calculated coefficients are an average value, the corresponding standard deviation describes the extent of heterogeneous preferences within the sample.

\section{Subgroup testing: latent class analysis}

\section{Differences in the preferences according to structural variables}

Since the random parameter logit model showed certain heterogeneities in the sample, an explorative analysis was generated using a latent class model.

To identify possible subgroups, at first a two-class model was developed, followed by a three-class model. A model with four and more classes proved to be meaningfully uninterpretable because of the sample size. The Bayesian Information Criterion (BIC) was used to assess model quality as well as the model best determining existing heterogeneity in response behavior and to provide a probable allocation of the subjects per group. Finally, the three-class model could be identified as suitable. Table 3 shows the results of the preference analysis separated for the three classes (Fig. 3).

Overall, there were five structural and personality traits which influenced the respective probability of the subjects belonging to one class. As indicators for the group differences, "age" (age groups), the "subjective assessment of one's own state of health" (based on Likert scale), the "time since diagnosis" (time span), "medical care" (mainly treated by GP or specialist) as well as the "presence of a depression" (diagnosed as co-morbidity) were identified. The three preference patterns were less dependent on the other sociodemographic and therapy-specific factors (Table 4). 
Table 1 Socio-demographic structure of patient sample
$N=227(\%)$

\section{Gender}

Male

$150(66.1)$

Female

77 (33.9)

Age

18-29 years

$3(1.3)$

30-39 years

18 (7.9)

40-49 years

$32(14.1)$

$50-59$ years

74 (32.6)

60-69 years

77 (33.9)

70-79 years

$22(9.7)$

$\geq 80$ years

$1(0.4)$

Mean (SD)

$56.66(11.21)$

Education level

No degree

31 (13.7)

Junior/middle school certificate

77 (33.9)

Intermediate high school certificate. secondary school certificate)

$11(4.8)$

Vocational school/advanced technical certificate

$17(7.5)$

Abitur. high school diploma in Germany: university entrance qualification

40 (17.6)

Technical college degree

$46(20.3)$

University degree or higher

$5(2.2)$

Doctorate

$31(13.7)$

Other degree

Marital status

Married

$-$

Widowed

$128(56.4)$

Divorced or separated

$16(7.0)$

Single

35 (15.4)

$33(14.5)$

In a relationship. but not married

$15(6.6)$

Other

Current HbA1c level

$$
\leq 6 \%
$$

$6.1-7.0 \%$

$14(6.2)$

$7.1-8.0 \%$

$91(40.1)$

85 (37.4)

$8.1 \% 9.0 \%$

$21(9.3)$

$>9.0 \%$

$9(4.0)$

Not sure

$7(3.1)$

Frequency of mild hypoglycemia (last month)

No mild hypoglycemia

37 (16.3)

1 mild hypoglycemia

$54(23.8)$

2 mild hypoglycemia

40 (17.6)

3 mild hypoglycemia

$17(7.5)$

4 mild hypoglycemia

$5(2.2)$

$5(2.2)$

$6(2.6)$

Not sure

$52(22.9)$

$11(4.8)$

Not sure (ever)

Frequency of severe hypoglycemia (since diagnosis)

1 severe hypoglycemia

$19(8.4)$

More than 1 severe hypoglycemia

$16(7.0)$

Not sure

$10(4.4)$

No severe hypoglycemia 
Table 2 Random parameter logit model (coefficients and standard deviations)

\begin{tabular}{|c|c|c|c|c|c|c|c|}
\hline Attribute level & Coeff. & SE & $Z$ & $p$ & CI 95\%-low & CI 95\%-high & Level diff. \\
\hline $\begin{array}{l}\text { Change in the long-term blood glucose levels } \\
\text { (HbA1c level) }\end{array}$ & & & & & & & 1.775 \\
\hline Worsening at $9.5 \%$ & -0.918 & 0.120 & -7.640 & 0.000 & -1.153 & -0.682 & \\
\hline No change at $9.5 \%$ & -0.357 & 0.100 & -3.570 & 0.000 & -0.552 & -0.161 & \\
\hline Improvement at $9.5 \%$ & 0.228 & 0.092 & 2.470 & 0.013 & 0.047 & 0.409 & \\
\hline Worsening at $7.5 \%$ & -0.285 & 0.095 & -3.000 & 0.003 & -0.471 & -0.099 & \\
\hline No change at $7.5 \%$ & 0.474 & 0.093 & 5.100 & 0.000 & 0.292 & 0.656 & \\
\hline Improvement at $7.5 \%$ & 0.857 & 0.127 & 6.740 & 0.000 & 0.608 & 1.106 & \\
\hline Risk of myocardial infarction (over 10 years) & & & & & & & 1.854 \\
\hline High $(30 \%)$ & -0.975 & 0.077 & -12.590 & 0.000 & -1.127 & -0.823 & \\
\hline Moderate (20\%) & 0.096 & 0.052 & 1.840 & 0.065 & -0.006 & 0.199 & \\
\hline Low $(10 \%)$ & 0.879 & 0.075 & 11.710 & 0.000 & 0.732 & 1.026 & \\
\hline Risk of stroke (over 10 years) & & & & & & & 1.255 \\
\hline High $(15 \%)$ & -0.741 & 0.065 & -11.400 & 0.000 & -0.868 & -0.614 & \\
\hline Moderate (10\%) & 0.227 & 0.053 & 4.250 & 0.000 & 0.122 & 0.332 & \\
\hline Low $(5 \%)$ & 0.514 & 0.062 & 8.260 & 0.000 & 0.392 & 0.636 & \\
\hline Occurrence of mild hypoglycemia per month & & & & & & & 0.659 \\
\hline 2 mild hypoglycemia per month & -0.301 & 0.057 & -5.290 & 0.000 & -0.412 & -0.189 & \\
\hline 1 mild hypoglycemia per month & -0.057 & 0.052 & -1.090 & 0.274 & -0.158 & 0.045 & \\
\hline 0 mild hypoglycemia per month & 0.358 & 0.060 & 5.960 & 0.000 & 0.240 & 0.475 & \\
\hline Risk of depression (over 5 years) & & & & & & & 0.523 \\
\hline High $(20 \%)$ & -0.287 & 0.057 & -5.040 & 0.000 & -0.398 & -0.175 & \\
\hline Moderate (15\%) & 0.051 & 0.052 & 0.990 & 0.324 & -0.050 & 0.152 & \\
\hline Low $(10 \%)$ & 0.236 & 0.059 & 4.010 & 0.000 & 0.121 & 0.351 & \\
\hline Occurrence of severe hypoglycemia per year & & & & & & & 2.765 \\
\hline 2 severe hypoglycemia per year & -1.387 & 0.106 & -13.090 & 0.000 & -1.594 & -1.179 & \\
\hline 1 severe hypoglycemia per year & 0.008 & 0.050 & 0.160 & 0.869 & -0.090 & 0.107 & \\
\hline \multirow[t]{2}{*}{0 severe hypoglycemia per year } & 1.378 & 0.104 & 13.250 & 0.000 & 1.174 & 1.582 & \\
\hline & $\mathrm{SD}^{*}$ & SE & $Z$ & $p$ & CI 95\%-low & CI 95\%-high & \\
\hline \multicolumn{8}{|l|}{$\begin{array}{l}\text { Change in the long-term blood glucose levels } \\
\text { (HbA1c-level) }\end{array}$} \\
\hline Worsening at $9.5 \%$ & 0.878 & 0.136 & 6.480 & 0.000 & 0.612 & 1.1434 & \\
\hline No change at $9.5 \%$ & -0.433 & 0.196 & -2.210 & 0.027 & -0.817 & -0.0493 & \\
\hline Improvement at $9.5 \%$ & 0.096 & 0.172 & 0.560 & 0.578 & -0.241 & 0.4330 & \\
\hline Worsening at $7.5 \%$ & 0.425 & 0.170 & 2.510 & 0.012 & 0.093 & 0.7581 & \\
\hline No change at $7.5 \%$ & 0.092 & 0.137 & 0.670 & 0.503 & -0.176 & 0.3596 & \\
\hline Improvement at $7.5 \%$ & -1.057 & 0.423 & -2.500 & 0.012 & -1.887 & -0.2279 & \\
\hline \multicolumn{8}{|l|}{ Risk of myocardial infarction (over 10 years) } \\
\hline High $(30 \%)$ & 0.534 & 0.078 & 6.850 & 0.000 & 0.381 & 0.6871 & \\
\hline Moderate (20\%) & -0.150 & 0.068 & -2.190 & 0.028 & -0.284 & -0.0158 & \\
\hline Low $(10 \%)$ & -0.384 & 0.110 & -3.510 & 0.000 & -0.599 & -0.1694 & \\
\hline \multicolumn{8}{|l|}{ Risk of stroke (over 10 years) } \\
\hline High $(15 \%)$ & 0.284 & 0.091 & 3.110 & 0.002 & 0.105 & 0.4634 & \\
\hline Moderate (10\%) & 0.111 & 0.086 & 1.300 & 0.195 & -0.057 & 0.2786 & \\
\hline Low $(5 \%)$ & -0.395 & 0.124 & -3.170 & 0.002 & -0.639 & -0.1511 & \\
\hline \multicolumn{8}{|l|}{ Occurrence of mild hypoglycemia per month } \\
\hline 2 mild hypoglycemia per month & 0.141 & 0.092 & 1.540 & 0.124 & -0.039 & 0.3212 & \\
\hline 1 mild hypoglycemia per month & 0.129 & 0.084 & 1.540 & 0.123 & -0.035 & 0.2928 & \\
\hline 0 mild hypoglycemia per month & -0.270 & 0.127 & -2.130 & 0.033 & -0.519 & -0.0216 & \\
\hline
\end{tabular}


Table 2 (continued)

$\begin{array}{llllll}\text { SD* } & \text { SE } & Z & p & \text { CI 95\%-low } & \text { CI 95\%-high }\end{array}$

Risk of depression (over 5 years)

High (20\%)

$\begin{array}{llllll}-0.162 & 0.069 & -2.340 & 0.019 & -0.297 & -0.0266 \\ -0.121 & 0.089 & -1.360 & 0.175 & -0.296 & 0.0539 \\ 0.283 & 0.114 & 2.480 & 0.013 & 0.059 & 0.5074\end{array}$

Low (10\%)

Occurrence of severe hypoglycemia per year

$\begin{array}{lllllll}2 \text { severe hypoglycemia per year } & 1.277 & 0.104 & 12.250 & 0.000 & 1.073 & 1.4809 \\ 1 \text { severe hypoglycemia per year } & 0.023 & 0.079 & 0.290 & 0.773 & -0.132 & 0.1775 \\ \text { 0 severe hypoglycemia per year } & -1.299 & 0.137 & -9.450 & 0.000 & -1.569 & -1.0300\end{array}$

$N=227$. Obs.: 5448; Log Lik: - 1305.14; AIC: 2670.29; BIC: 2868.38

*The sign of the estimated standard deviations is irrelevant: interpret them as being positive

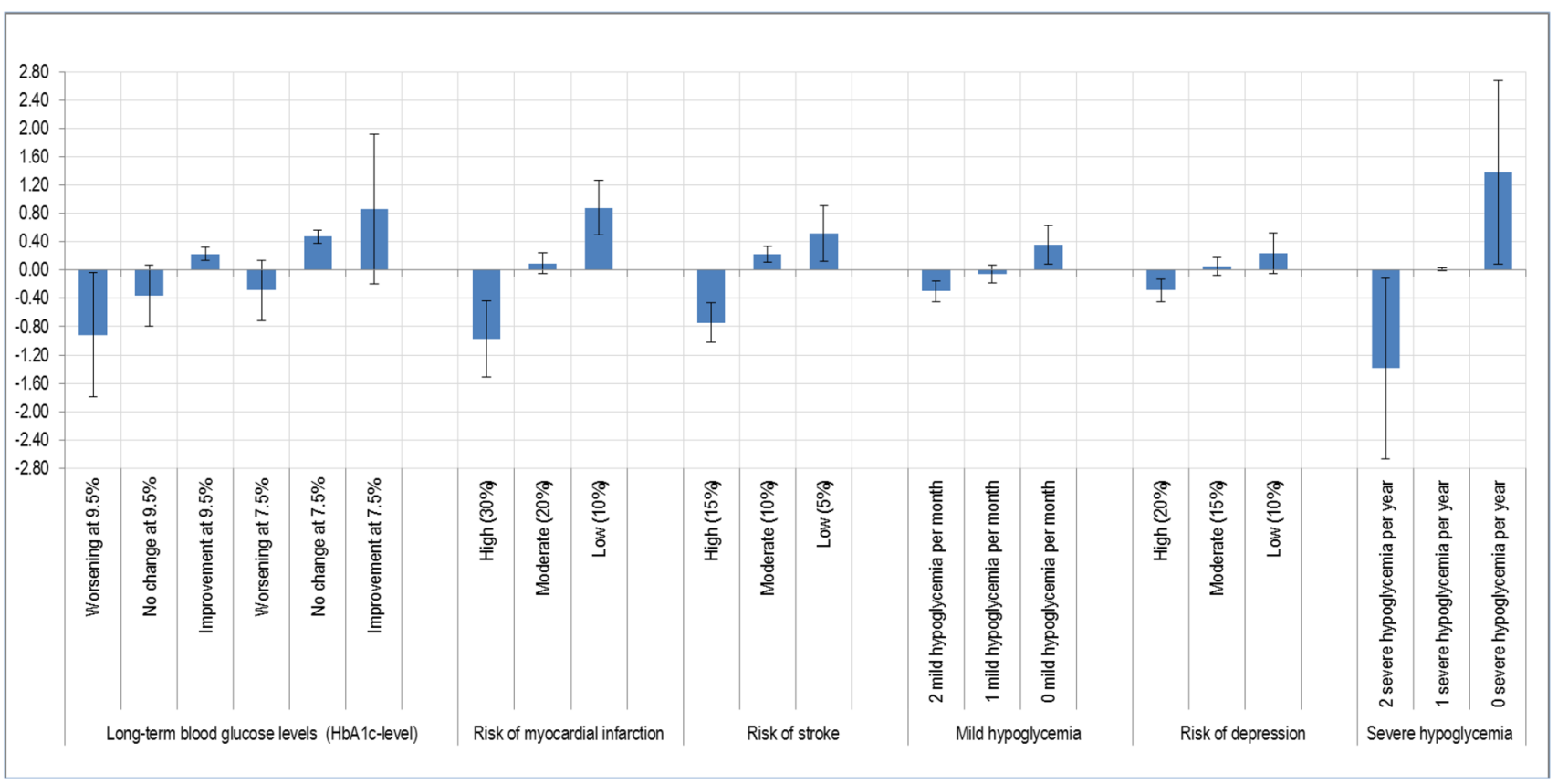

Fig. 2 Random parameter model with standard deviations $(N=227)$

\section{Preference pattern of class 1}

Preference pattern The preference pattern of the first class $[N=73(32.2 \%)]$ is characterized by a very high rating of severe hypoglycemia, and a clear division of the relevance of the attributes. In this group "occurrence of severe hypoglycemia" is followed by the attributes "risk of heart attack," "risk of stroke" and the "occurrence of mild hypoglycemia" and the "change in the long-term blood glucose levels." These attributes are close to each other in their valiancy for the group, the difference of the preference weights is rather small. However, the distance to the first attribute is very high. Finally, the "risk of depression" follows at an even greater distance. This attribute has a weakly significant coefficient only for the lowest level, which would allow the presumption that this side effect has no or very little influence on the decision of this subpopulation (Fig. 4).

Evaluation of structural variables In class 1 , the age group of the 40-69 years is most frequently represented $(N=64$, $88 \%$ ). In the comparison of the classes, the share of $84 \%$ of persons with statutory insurance is the lowest in this class.

Class 1 comprises $67 \%$ of all persons of the total sample that were "completely dissatisfied" with their health. In addition, $60 \%$ of respondents who reported having experienced more than four mild hypoglycemias last month were grouped in this class.

The participants classified in class 1 also reported an above-average $\mathrm{HbA} 1 \mathrm{c}$ level of more than $8.1 \%(N=11 / 73$, $15 \%)$. This is the highest proportion of all classes. The same 
Table 3 Latent class analysis (3-class-model)

\begin{tabular}{|c|c|c|c|c|c|c|c|c|c|}
\hline \multirow[t]{2}{*}{ Attribute level } & \multicolumn{3}{|l|}{ Class 1} & \multicolumn{3}{|l|}{ Class 2} & \multicolumn{3}{|l|}{ Class 3} \\
\hline & Coeff. & SE & $p$ & Coeff. & SE & $p$ & Coeff. & SE & $p$ \\
\hline \multicolumn{10}{|c|}{$\begin{array}{l}\text { Change in the long-term blood glucose } \\
\text { levels (HbA1c-level) }\end{array}$} \\
\hline Worsening at $9.5 \%$ & -0.093 & 0.272 & 0.732 & -1.236 & 0.131 & 0.000 & 0.057 & 0.279 & 0.838 \\
\hline No change at $9.5 \%$ & -0.420 & 0.220 & 0.056 & -0.305 & 0.108 & 0.005 & -0.318 & 0.263 & 0.227 \\
\hline Improvement at $9.5 \%$ & 0.160 & 0.222 & 0.472 & 0.344 & 0.107 & 0.001 & -0.016 & 0.219 & 0.940 \\
\hline Worsening at $7.5 \%$ & -0.196 & 0.223 & 0.380 & -0.321 & 0.106 & 0.003 & -0.059 & 0.254 & 0.815 \\
\hline No change at $7.5 \%$ & 0.077 & 0.220 & 0.727 & 0.633 & 0.109 & 0.000 & 0.052 & 0.218 & 0.812 \\
\hline Improvement at $7.5 \%$ & 0.472 & 0.228 & 0.039 & 0.884 & 0.121 & 0.000 & 0.285 & 0.269 & 0.290 \\
\hline \multicolumn{10}{|l|}{$\begin{array}{l}\text { Risk of myocardial infarction (over } \\
10 \text { years) }\end{array}$} \\
\hline High $(30 \%)$ & -0.645 & 0.170 & 0.000 & -0.481 & 0.075 & 0.000 & -2.081 & 0.304 & 0.000 \\
\hline Moderate (20\%) & 0.070 & 0.130 & 0.591 & 0.027 & 0.061 & 0.664 & 0.400 & 0.146 & 0.006 \\
\hline Low $(10 \%)$ & 0.575 & 0.151 & 0.000 & 0.454 & 0.071 & 0.000 & 1.681 & 0.264 & 0.000 \\
\hline \multicolumn{10}{|l|}{ Risk of stroke (over 10 years) } \\
\hline High (15\%) & -0.606 & 0.162 & 0.000 & -0.492 & 0.073 & 0.000 & -1.494 & 0.218 & 0.000 \\
\hline Moderate (10\%) & 0.049 & 0.119 & 0.683 & 0.143 & 0.059 & 0.015 & 0.587 & 0.143 & 0.000 \\
\hline Low $(5 \%)$ & 0.558 & 0.144 & 0.000 & 0.349 & 0.069 & 0.000 & 0.907 & 0.186 & 0.000 \\
\hline \multicolumn{10}{|c|}{$\begin{array}{l}\text { Occurrence of mild hypoglycemia per } \\
\text { month }\end{array}$} \\
\hline 2 mild hypoglycemia per month & -0.413 & 0.145 & 0.005 & -0.270 & 0.073 & 0.000 & -0.129 & 0.166 & 0.439 \\
\hline 1 mild hypoglycemia per month & -0.107 & 0.128 & 0.403 & 0.001 & 0.063 & 0.990 & -0.121 & 0.149 & 0.416 \\
\hline 0 mild hypoglycemia per month & 0.520 & 0.149 & 0.000 & 0.270 & 0.066 & 0.000 & 0.250 & 0.135 & 0.065 \\
\hline \multicolumn{10}{|l|}{ Risk of depression (over 5 years) } \\
\hline High $(20 \%)$ & -0.225 & 0.132 & 0.087 & -0.217 & 0.066 & 0.001 & -0.484 & 0.147 & 0.001 \\
\hline Moderate $(15 \%)$ & -0.095 & 0.131 & 0.467 & 0.068 & 0.061 & 0.269 & -0.057 & 0.142 & 0.691 \\
\hline Low $(10 \%)$ & 0.320 & 0.131 & 0.015 & 0.150 & 0.071 & 0.036 & 0.540 & 0.186 & 0.004 \\
\hline \multicolumn{10}{|c|}{$\begin{array}{l}\text { Occurrence of severe hypoglycemia per } \\
\text { year }\end{array}$} \\
\hline 2 severe hypoglycemia per year & -2.584 & 0.227 & 0.000 & -0.451 & 0.074 & 0.000 & -0.516 & 0.175 & 0.003 \\
\hline 1 severe hypoglycemia per year & -0.014 & 0.109 & 0.900 & 0.009 & 0.061 & 0.882 & -0.183 & 0.146 & 0.210 \\
\hline 0 severe hypoglycemia per year & 2.597 & 0.224 & 0.000 & 0.442 & 0.076 & 0.000 & 0.699 & 0.197 & 0.000 \\
\hline Patients & $N=73(32.2 \%)$ & & & $N=107(47.1 \%)$ & & & $N=47(20.7 \%)$ & & \\
\hline Constant (SE) & $-0.2385(0.1911)$ & & & $-0.7588(0.2440)$ & & & (Reference) & & \\
\hline
\end{tabular}

applies to the fact that $40 \%$ of the respondents in class 1 are mainly cared for by a family physician. This is also the highest proportion of all three classes.

\section{Preference pattern of class 2}

Preference pattern The preference pattern of the second class $(N=107 ; 47.1 \%)$ differs significantly from class 1 .

Very striking in the evaluation of the preference pattern in class 2 is that the "change of the long-term glucose level" is also the most important attribute in both versions of the compound attribute. A change at an initial value of $9.5 \%$ is weighted slightly higher than changes at $7.5 \%$ (Fig. 5).

This is identical to the overall evaluation in the random parameter logit model. The placement of the "risk for myocardial infarction" in the first three places is identical to class 1 . The "occurrence of severe hypoglycemia" follows closely. Compared to class 1 , the "risk of stroke" is ranked fifth. However, it is noticeable in the analysis of class 2 that all attributes in ranks 3-6 are in total denser. The "occurrence of mild hypoglycemia" occupies the penultimate position. As in class 1, "risk of depression" ranks in the last place.

Evaluation of the structural variables The persons grouped in the preference pattern of class 2 above-average said to be aged between 18 and 39 years $(N=14 / 21$ in the total sample, 67\%). Regarding the self-reported state of health, it is noticeable that $100 \%$ of all patients in the total sample, who rated their health as "very good" are grouped in 


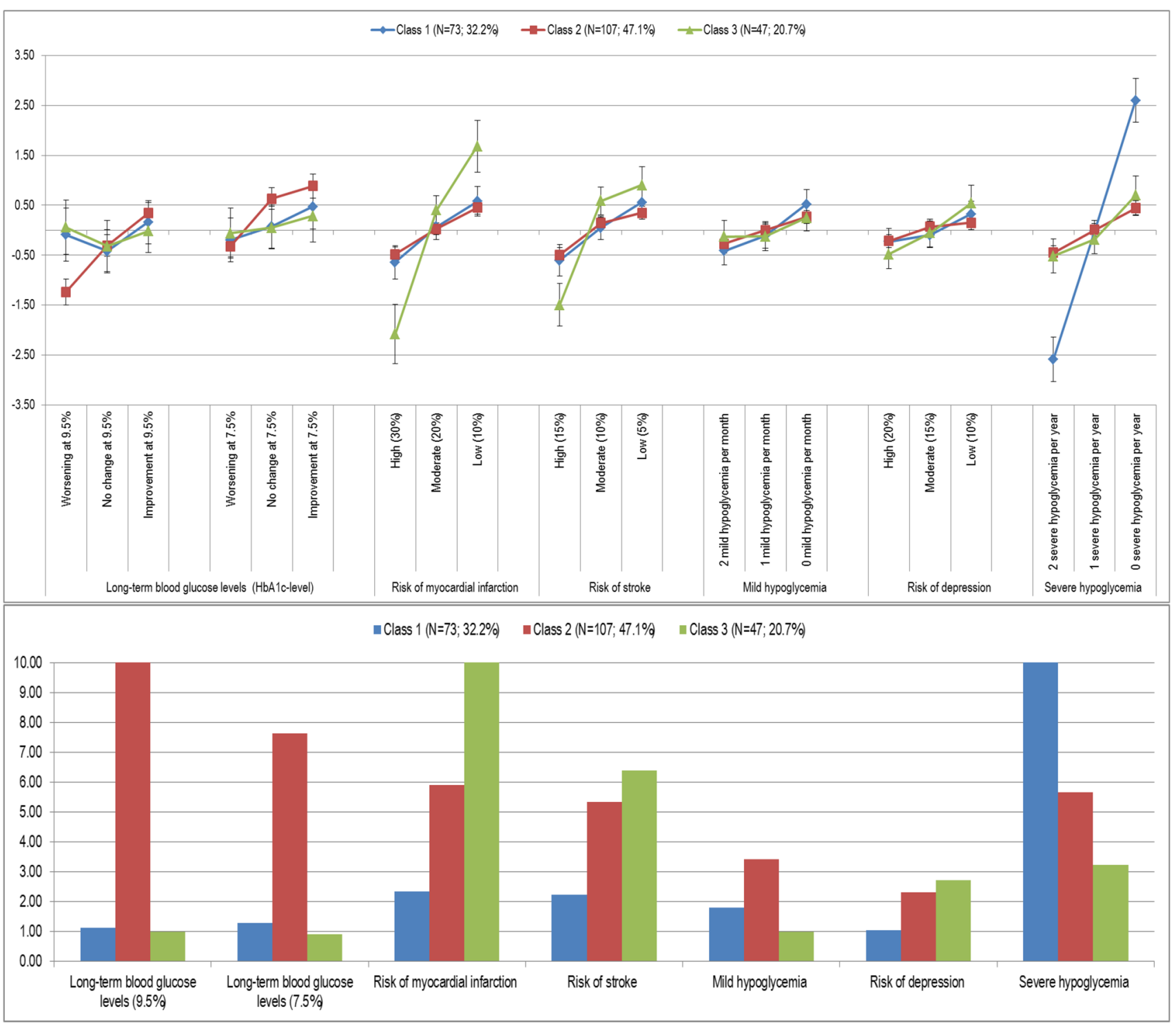

Fig. 3 Evaluation of the preference patterns for class 1, 2 and $3(95 \% \mathrm{CI})$ and normalized preference pattern class 1, 2 and 3

class $2(N=5 / 5)$. In class 2 , there are also above-average numbers of patients with a current $\mathrm{HbA} 1 \mathrm{c} \leq 6.0 \%$ as well as persons who have never experienced a severe hypoglycemia $(N=90 / 181$ in the total sample, 50\%). This accounts for $84 \%$ within this class $(N=90 / 107)$ and represents the highest percentage within the three classes. Furthermore, only $17 \%$ of class 2 participants reported to be diagnosed with depression as a co-morbidity of diabetes. This represents the smallest share of the three classes.

\section{Preference pattern of class 3}

Preference pattern A three-part division of the relative importance of the attributes is characteristic of the preference pattern in class $3(N=47 ; 20.7 \%)$. Unlike the first two groups, the preference pattern in this class is not determined by a characteristic of the glycemic setting, but by co-morbidities of diabetes. The "risk of myocardial infarction" is clearly placed on the first rank. It is followed by another comorbidity with "risk of stroke", but with a smaller distance than in the first two classes. The "second" division of attributes is formed by the "occurrence of severe hypoglycemia" and "risk of depression" on the places 3 and 4 . To this extent, this group differs significantly from the other two and also the random parameter logit model. It is important to note that the risk of depression is ranked fourth (Fig. 6) and the three least important characteristics of "occurrence of mild hypoglycemia per month" (5th place) and the "change of the long-term glucose level" (place 6 for the initial level of $9.5 \%$ and place 7 for changes from $7.5 \%$ ) have significance 
Table 4 Structural and personality traits per class

\begin{tabular}{llll}
\hline Structural and personality traits & Class 1 & Class 2 & Class 3 \\
\hline Age & & & \\
$18-39$ years & & ++ & \\
$40-69$ years & ++ & & - \\
$\geq 70$ years & & & + \\
Subjective assessment of own health & & ++ & \\
Excellent/ very good & & & - \\
Completely dissatisfied & ++ & & \\
Time of diagnosis & & & -- \\
$\leq 1$ year & & ++ & -- \\
2-5 years & + & & ++ \\
$>5$ years & - & & + \\
Co-morbidity: depression & + & -- & \\
Medical care by & & & \\
General Practitioner/family physician & + & & \\
Diabetes specialist practice & & + &
\end{tabular}

,--- low number of respondents,,+++ high number of respondents

values of $p>0.1$ for all coefficients. This allows the assumption that both attributes did not affect the decision of this subpopulation.

Evaluation of structural variables Individuals who were grouped in the preference pattern of class 3 above-average reported to be male $(N=35 / 47,75 \%)$. In addition, the largest share of pensioners $(N=29 / 47,61 \%)$ of all three groups is in class 3 . As a result, respondents in class 3 above-average reported the age group of $\geq 70$ years $(15 \%$, the highest proportion of all classes). The proportion of participants who have already experienced mild hypoglycemia is also highest in this class $(N=40 / 47,85 \%)$.

In addition, the participants in this class are very experienced with their diabetes. $85 \%$ reported having been diagnosed more than 5 years ago. This is the highest proportion of all three classes.

\section{Discussion \\ Descriptive results}

The study sample shows a 60/40 distribution of gender in the overall sample for the benefit of the male respondents. This corresponds roughly to the current prevalence and incidence rate in Germany, which also describes a slight accumulation of type II diabetes in the male population [43].

With regard to the level of education, the sample shows an approximate normal distribution in the education level, with slight shifts in favor of the university degree. Identical to other studies, most included subjects were married.

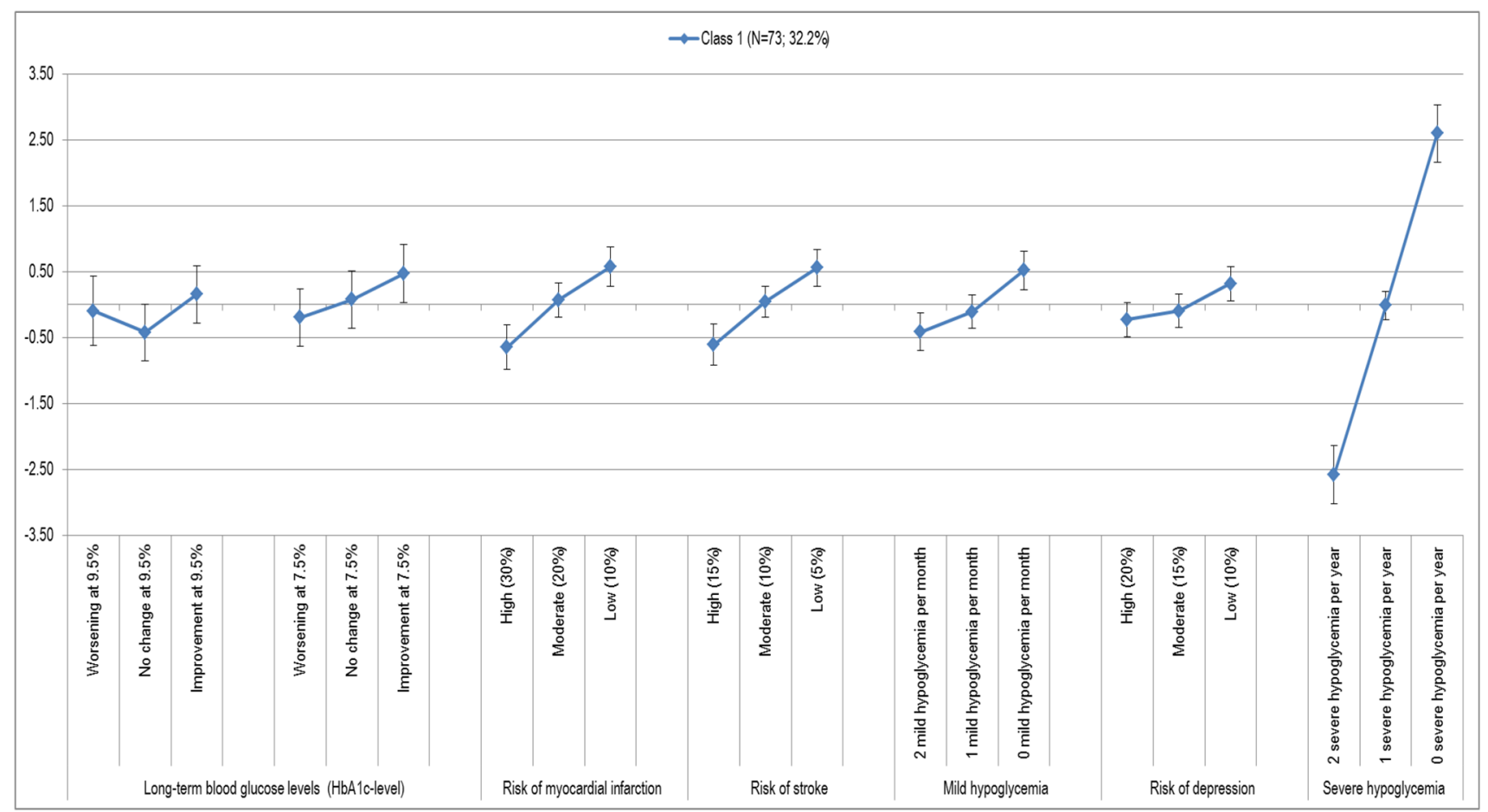

Fig. 4 Preference pattern class 1 (95\% CI) 


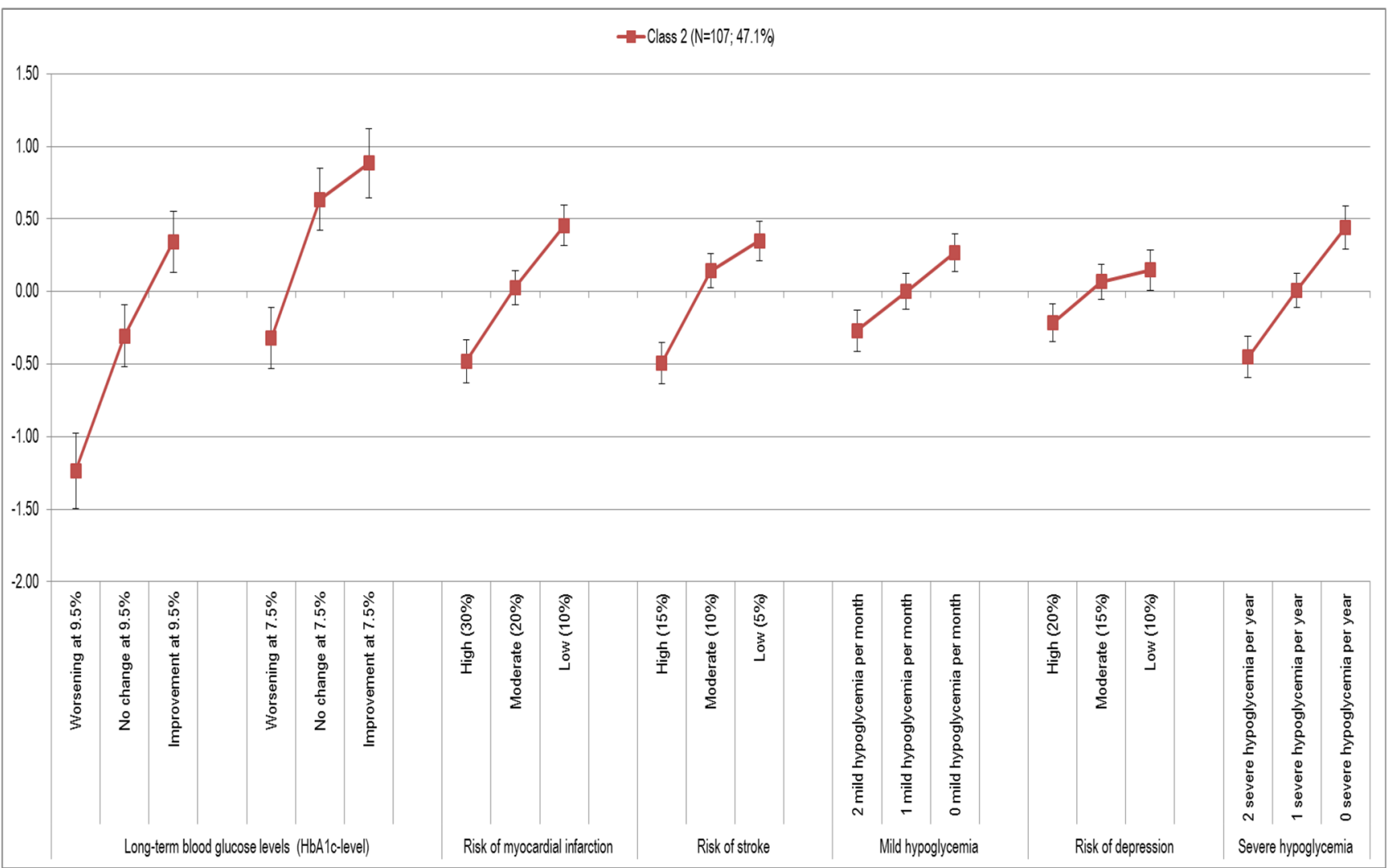

Fig. 5 Preference pattern class 2 (95\% CI)

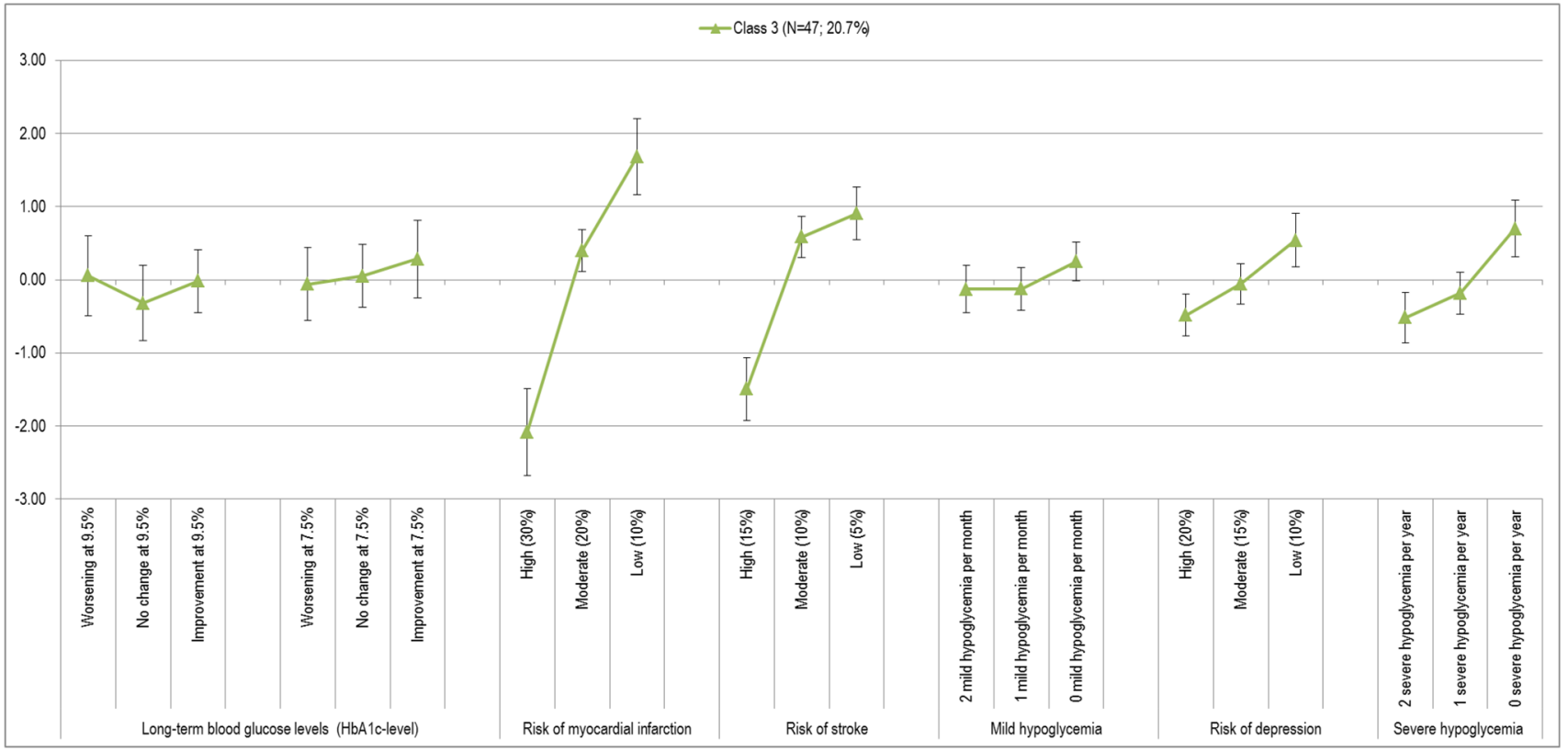

Fig. 6 Preference pattern class $3(95 \%$ CI) 
It is striking that the study sample is very experienced with diabetes. $42.3 \%$ were diagnosed between 10 and 20 years ago, another $11.0 \%$ even more than 20 years ago.

The present study shows a comparable number of diabetic patients treated with insulin therapy compared to other European preference studies in diabetes type II. While the number of subjects in Aristides et al. was $N=290$ [44], the current study recruited a total of $N=227$ diabetic patients. Guimarães et al. recruited 274 patients, but not exclusively those with type II [45, 46]. Mühlbacher et al. interviewed $N=626$ patients with type II diabetes, but the focus here was on therapy with oral antidiabetics [47].

\section{Rankings and the importance of patient-relevant endpoints}

In the conditional logit model as well as the random parameter logit model, all six included attributes had a significance level of $p \leq 0.01$ (99\%) for at least two levels. From this, it can be concluded that the decision-making model included patient-relevant properties. The results of the DCE show that efficacy dominates the side effects in importance. It is noticeable that the "occurrence of severe hypoglycemia" was rated markedly higher, than the "change in the long-term blood glucose levels" or the secondary diseases in almost all analyses. In addition, the Latent Class analysis provides clear indications that there are strong differences between different patient groups and that the overall picture of the random parameter logit model must be considered more differently.

\section{Occurrence of severe hypoglycemia}

Patients know about the essential meaning of the attribute. This is reflected in the DCE. In the random parameter model, the "change of the long-term glucose levels (HbAlc value)" occupies the first place by far. This is also in line with the results of the AHP. However, it must be mentioned here that the "occurrence of severe hypoglycemia" was placed to the first rank only by the experts. In patients, the characteristic was of lesser importance.

\section{Risk of myocardial infarction (over 10 years)}

The risk of a myocardial infarction is significantly increased in diabetics compared to non-diabetics. Over a period of 10 years, the incidence of heart disease in healthy people is around 3\%, while this rate is between 15 and $20 \%$ for diabetics [48]. The "risk of myocardial infarction (over 10 years)" was rated second highest in the overall analysis of the random parameter logit model following the occurrence of severe hypoglycemias. A possible explanation for this is that the affected persons are aware of the correlations between hypoglycemia and the increased risk of myocardial infarction. It has been shown in studies that the first cardiovascular event occurs only an average of 1.5 years after the first onset of hypoglycemia [49].

Patients thus seem to combine a limitation of their performance and a reduction in their quality of life. Nevertheless, the experience with cardiovascular disease seems to be relatively small in the included sample. Only $7.5 \%$ of respondents stated that they had already had a heart attack in the past.

\section{Risk of stroke (over 10 years)}

Like the risk of myocardial infarction, risk of stroke is significantly increased in patients with diabetes mellitus type II compared to the healthy population [48]. This is obviously also registered by the patients and correspondingly taken into account in the evaluation of therapeutic alternatives. Asked about the average 10 years-risk for a patient with diabetes to suffer from a stroke, the majority of patients $(75.7 \%)$ responded " $10-15 \%$ " or "even more than $15 \%$ ".

Hence, the "risk of stroke (over 10 years)" (taking into account the level difference between the best and the worst level) ranks third in the random parameter logit model.

\section{Change in the long-term blood glucose levels}

The "change of the long-term blood glucose levels" is weighted fourth and fifth in the random parameter logit model (considering the difference between the best and the worst). The change in the HbAlc value is thus of great importance and a change at an initial value of $9.5 \%$ is weighted slightly higher than changes at $7.5 \%$.

The high importance of the HbAlc value has been demonstrated in several studies [50, 51]. The first rank in all models of the present study underlines this high impact and is, therefore, in agreement with the currently available literature on other preference studies. Analogously to the study of Bøgelund et al. [52] and Hauber et al. [53], the attribute "long-term blood glucose level" could be determined as a very important patient-relevant property. Similar results are also found in the study by Mühlbacher/Bethge. Here the "change of the long-term blood glucose" was the second most important criterion in the (hypothetical) therapy decision [47]. The correct setting of the long-term sugar value and the associated short-term and especially long-term prevention of secondary diseases is the ultimate goal of any diabetic therapy [54]. Thus, patient perspective and endpoint relevance are consistent with clinical studies. 


\section{Occurrence of mild hypoglycemia}

The occurrence of mild hypoglycemias per month is placed in sixth place. Hence, the results in this study seem to differ from other preference studies in the evaluation of treatment options in the treatment of type II diabetes. The study by Gelhorn et al. showed a possible hypoglycemia in the first place followed by the adjustment of the HbA1c value [55]. The study by Aristides et al. was able to demonstrate the high significance of the possible hypoglycemia from the patient's perspective. In their preference study in insulintreated patients the occurrence of hypoglycemia was most important for the patients [44]. However, it must be borne in mind that these preference studies did not distinguish between the occurrence of mild and severe hypoglycemia. This distinction and the consideration of both forms is a special feature of the present study. Gelhorn et al. as well as Aristides et al. related only to "possible hypoglycemias". If this fact is considered, the results are concordant, because the current study also shows that "hypoglycemias" are the first place and could be identified as crucial patient-relevant characteristic.

Many of the patients surveyed know mild hypoglycemias. When asked whether they had ever experienced mild hypoglycemia, a total of $72.2 \%$ of respondents answered "yes". However, a mild hypoglycemia was only fifth in overall evaluation. It can be assumed that due to the familiarity with this effect and its less severe symptoms/consequences it is of less importance for the patients.

\section{Risk of depression (over 5 years)}

Along with diabetes, the risk for further complications, such as depression or dementia, increases [17, 56]. Diabetes doubles the risk of depression compared to a healthy person. However, the "risk of depression" is of little or no relevance to diabetic patients facing a decision about a care program. This is shown both in the random parameter logit, as well as in the latent class analysis and is expressed by the relatively low coefficients and the lack of significance in some levels. Thus, this attribute occupies only the last place (taking into account the difference between the best and the worst.) In response to the question of whether a depression/depressive episode has been diagnosed following diabetes, $22.5 \%$ of respondents answered "yes", $67.0 \%$ answered in the negative, and $10.6 \%$ were "not sure".

\section{Heterogeneities: latent class analysis}

Based on the model quality criteria, a three-class model was chosen. The three groups of participants show clearly different weights of the therapeutic properties. The number of participants is not fully equally distributed to the three classes: as expected, one group of respondents considers changing the long-term blood glucose (HbAlc value) as the main goal. Another group is solely interested in the short-term effectiveness of diabetes management and thus the reduction in the number of severe hypoglycemias. Surprisingly, another group assessed the risk of cardiovascular problems, such as heart attacks and strokes, the highest.

\section{Class 1: Focus on the occurrence of severe hypoglycemia}

The preference pattern of class $1(N=73)$ is determined by a focus on "occurrence of severe hypoglycemias per year" (LD 5.181, rank 1). The risk of myocardial infarction (over 10 years) (LD 1.219, rank 2) and the risk of stroke (over 10 years) (LD 1164, rank 3 ) follow at a very great distance. Respondents clearly rate higher numbers of severe hypoglycemia negatively. The focus on the reduction of the frequencies of severe hypoglycemia dominates all other characteristics of care.

Striking in this class is a very clear "threefold" of the attributes. The occurrence of severe hypoglycemias is followed by four attributes ("risk of myocardial infarction", "risk of stroke", "occurrence of mild hypoglycemia", "change of the long-term blood glucose level") that are closely related in terms of their value for the group. This is illustrated by the small difference in the preference coefficients of these four features. Finally, the "risk of depression" follows at an even greater distance. For this attribute, a weakly significant coefficient can only be calculated for the lowest level, which allows the presumption that this side effect has little or no influence on the decision of this subpopulation.

Class 1 clearly highlights the short-term and immediate success of diabetes management ("occurrence of severe hypoglycemia"). There is a nearly linear course in which the absence of severe events $(0 \times$ per year) is rated markedly higher than " 1 severe hypoglycemia per year". These characteristics, in turn, clearly dominates the worst level " $2 \times$ per year".

This preference pattern is also reflected in the evaluation of the structural variables. It is striking that the class combines the largest proportion of patients who have already experienced severe hypoglycemia (53\% of all respondents). This can serve as an explanation approach for the high value of the attribute.

In addition, $67 \%$ of all persons in the overall sample who said they were "completely dissatisfied" with their health have high probabilities of belonging to class 1 . This fact might also explain why the short-term and potentially directly life-threatening (accompanying) symptoms of diabetes-severe hypoglycemia, myocardial infarction and stroke-are among the top places. Patients in this group are 
concerned about their health and want to avoid these serious effects.

Furthermore, 54\% of all respondents who prefer the doctor to make the final decision on treatment are found in class 1. In addition, $40 \%$ of the respondents in class 1 are mainly cared for by the family physician. This is also the highest proportion of all three classes.

In this respect, it can be assumed that the management of diabetes and the doctor-patient communication in this group have a clear influence on the patient's therapeutic preferences. Patients in class 1 seem to follow the recommendations of their (family) doctors on their treatment or everyday life.

\section{Class 2: Focus on changing the long-term blood glucose}

The objective ranking in class $2(N=107)$ is clearly deviating from class 1 . Like the first class, a triple division is also recognizable, but with smaller distances in importance. In the second class the "change of the long-term blood glucose levels" is most important (LD 2120). This is particularly striking, since this characteristic is placed first only in this class. In the other two classes, the "change of the long-term blood glucose levels" occupies the fifth place. The ranking of the "risk for myocardial infarction" (LD 0.935) in the second place is identical to class 1 , but the difference to the most important attribute is significantly lower than in the first class. With "occurrence of severe hypoglycemias per year" (LD 0.893) and "risk of stroke" (LD 0.841) on the places 3 and 4, it is followed by attributes, which are relatively similar in their relative importance to "risk of myocardial infarction". These three attributes appear to be valued by the patients in combination.

Class 2 clearly emphasizes the long-term and lasting adjustment of the blood glucose in the context of diabetes management. Only in this class a nearly linear course over all levels of the attribute can be seen. For both hypothetical "initial values" of 7.5 and $9.5 \%$ an improvement is valued significantly higher than a constant value. Both clearly dominate the worst level of "deterioration". It is also noticeable that the changes at an initial value of $7.5 \%$ each achieve higher coefficients and consequently were seen as more relevant by the patients in this subgroup.

This preference pattern is also reflected in the evaluation of the structural variables. It is noteworthy that the majority of respondents with a current $\mathrm{HbA} 1 \mathrm{c} \leq 6.0 \%$ and $49 \%$ of all respondents in the range of 6.1-7.0\% were grouped in class 2 (based on the individual probability of class membership). In addition, patients in this class are relatively newly diagnosed with diabetes.

For this class, the expert care and the structured management of their diabetes seem particularly interesting. This is reflected in the fact that most of respondents who are enrolled in a care program, such as DMP, are grouped in class 2 . In addition, patients in this class prefer treatment in diabetes centers or specialist practices.

\section{Class 3: Focus on cardiovascular events}

The third group shows a different picture. For class 3 $(N=47)$ the focus is on avoiding cardiovascular events. Diabetes is a risk to the heart and blood vessels and can lead to congenital damage such as circulatory disorders, increased strokes and heart attacks. This seems particularly relevant to the patient in this class. Consequently, the "risk of heart attack (over 10 years)" (LD 3762) is the most important attribute that dominates all other characteristics. In the second place, a second cardiovascular event follows-"risk of stroke (over 10 years)" (LD 2401). Patients in class 3 focus solely on the risk of these secondary diseases, regardless of the frequency of hypoglycemia or adjustment of the longterm glucose level.

In this class, the "risk of depression (over 5 years)" is ranked fourth and hence ranked highest in the comparison of the three classes. This supports the assumption that the patients in this group focus exclusively on long-term followup and secondary diseases when choosing a care program.

Consequently, in this class, the "change of the long-term glucose level" and the "occurrence of mild hypoglycemia per month" fall back on the penultimate and last position. These two attributes do not produce any significant coefficients for any of the levels and are thus irrelevant for this patient group.

$82 \%$ in class 3 reported suffering from hypertension. This is the highest proportion of all classes. Since hypertension is another risk factor for cardiovascular events, a further explanation for the shown preference pattern could be included herein. In addition, the participants in this class are very experienced with their diabetes. $85 \%$ in the class reported having received the diagnosis more than 5 years ago. This is also the highest proportion of all three classes. Finally, above average, they stated to be male. It can be concluded that these experienced, elderly patients are very sensitive to long-term consequences of their diabetes with regard to cardiovascular events, regardless of the short-term effectiveness of a diabetes management.

\section{Limitations}

Although the use of the DCE method in the field of diabetes therapy could be demonstrated, some limitations are to be taken into account in the analysis, interpretation and generalization of the data.

Respondents were recruited by means of an external service provider. This may have influenced the study population 
regarding individual parameters (selection bias) and cannot be verified in its entirety.

The use of the "forced choice" integrated into the DCE forced participants to choose one of the presented therapy alternatives. This does not necessarily reflect reality and does not mean that the patients would also choose the alternatives shown in reality. A non-forced choice is recommended to forecast willingness to pay or demand. Because this was not the objective of this study, this limitation appears reasonable. The advantage of the chosen variant lies in the data quality.

Attributes in a DCE must be formulated in such a way that respondents clearly and concisely understand the meaning of the attribute. Especially risk attributes should be explained thoroughly in the course of the DCE to avoid mistakes based on difficulties in understanding probabilities and the concept of risk. Most recent studies apply a combination of quantitative description and visual support to present risk attributes. Regarding the number of risk attributes, some studies used the same number of risk and benefits attributes (e.g. [57]), other use more risk than benefit attributes (e.g. [58]) or less risk attributes (e.g. [59]). The use of risk attributes in DCEs is repeatedly highlighted as an area for further research. Basically, the number of risk attributes is discussed less critically than the way in which a risk attribute is to be communicated and presented/framed to respondents. Special attention is needed towards attributes involving a description of risk as risks are often perceived as difficult to interpret. The number of risk attributes within the recommended number of attributes in general in a DCE does not seem to influence the overall result. More important seems to be how respondents perceive and evaluate the risks presented. Since there is no guideline on how to present risk attributes, further research is needed on how to deal with or overcome framing effects [60, 61].

For the experiment, a d-efficient design with prior estimates was used. D-optimal designs attempt to maximize attribute level differences and might lead to lexicographic choice behavior. However, as D-optimal designs focus on the attribute level differences no prior estimates are used for constructing these designs.

The mixed logit model outperformed the conditional logit model in terms of model fit criteria and magnitude of coefficients. All coefficients in the mixed logit model were assumed to be normally distributed. Other distributions were not assumed to be applicable, e.g. uniform. This remains a limitation in the analysis.

In the latent class analysis, the parameter estimates for the middle level of "risk of depression" and "occurrence of severe hypoglycaemia" are not significant. Respondents seem to only value the extreme levels of these attributes. This finding was not yet analyzed in more detail, but it could also be a behavioral issue. Respondents might have clear preferences for the attributes, but behaviorally regard these attributes as a binary outcome. Further analyses will be run on this.

As other studies have shown, preferences can depend on cultural background, expectations and attitudes of the study sample, and the current health system as a context factor [62]. When interpreting and generalizing these results, it should be taken into account that the study was based on a German population and conducted in mid-2017.

Finally, preferences might be influenced by different circumstances. Hence, the given information on attributes and levels, the patient's background of experience, as well as cognitive abilities are decisive $[63,64]$. Preferences can thus vary depending on the decision context.

\section{Conclusion}

Diabetes as a chronic disease places high demands on the compliance and adherence of patients. The success of the therapy is determined by various factors such as adherence to the recommended blood glucose monitoring or the documentation of blood glucose profiles. The use of personalized approaches to diabetes management is discussed on an international level and the success has been demonstrated in the first studies. Studies show that personalized diabetes management can increase the effectiveness and efficacy of therapy and improve treatment outcomes [19-22].

Decisions on diabetes therapy and/or management are very complex and require trade-offs between possible outcomes and simultaneous risks and secondary diseases. The present data show that patients have the highest weight on the "occurrence of severe hypoglycemias per year". On the second place is "change of the long-term blood glucose level (HbA1c level)", followed by "risk of myocardial infarction (over 10 years)" (considering the 95\% confidence interval). Thus, the reduction of the metabolic derivate as well as the optimal adjustment of the HbA1c level within the framework of a possible choice of a management approach has the decisive importance for the diabetic patients.

Even if it appears surprising that the "occurrence of severe hypoglycemia" is weighted higher than the "change in long-term blood glucose level" from patients' perspective, this can be supported by current studies. In the sample, more than $75 \%$ of respondents stated that they were older than 50 years. According to recent studies from the USA, a "normal" setting of the blood glucose can already mean an over-therapy, especially in elderly and comorbid diabetic patients. For them, the risks outweigh the desired benefits of drug treatment [65].

Considering the limitations, the results are also valuable for the doctor-patient relationship and the diabetes management. The DCE provides a practical approach that can 
help improve communication between patients and care providers. This approach has the potential to support clinical and allocative decision-making and to improve the quality of interpretation of clinical data in the long term. Diabetes management and therapies can be designed more patientoriented based on the findings obtained. In addition, more effective and efficient care can be achieved and patient benefit increased [66].

Acknowledgements The authors would like to thank all survey participants.

Funding Open Access funding enabled and organized by Projekt DEAL. This study was financed by Roche Diagnostics Deutschland $\mathrm{GmbH}$, Grenzach.

Open Access This article is licensed under a Creative Commons Attribution 4.0 International License, which permits use, sharing, adaptation, distribution and reproduction in any medium or format, as long as you give appropriate credit to the original author(s) and the source, provide a link to the Creative Commons licence, and indicate if changes were made. The images or other third party material in this article are included in the article's Creative Commons licence, unless indicated otherwise in a credit line to the material. If material is not included in the article's Creative Commons licence and your intended use is not permitted by statutory regulation or exceeds the permitted use, you will need to obtain permission directly from the copyright holder. To view a copy of this licence, visit http://creativecommons.org/licenses/by/4.0/.

\section{References}

1. Bierwirth, R.A., Kohlmann, T., Moock, J., et al.: Diabetesbezogene Kosten und Therapiezufriedenheit bei ICT-behandelten Typ-2-Diabetikern in der ambulanten Versorgung: Ergebnisse der LIVE-COM-Studie. Medizinische Klinik-Intensivmedizin und Notfallmedizin 105(11), 792-801 (2010)

2. Heidemann, C., Du, Y., Scheidt-Nave, C.: Diabetes mellitus in Deutschland. GBE kompakt, Robert Koch-Institut (Hrsg.) 2(3):224 (2011).

3. Siegel, E.: Versorgungsstrukturen, Berufsbilder und professionelle Diabetesorganisationen in Deutschland. Deutscher Gesundheitsbericht Diabetes 2010, 23-33 (2011)

4. Schwarz, P.E.H., Landgraf, R.: Prävention des Diabetes-wie können wir Präventionsmaßnahmen umsetzen? Deutscher Gesundheitsbericht Diabetes 2011, 14-22 (2011)

5. Hauner, H., Köster, I., Schubert, I.: Trends in der Prävalenz und ambulanten Versorgung von Menschen mit Diabetes mellitus. Dtsch. Arztebl. Int. 104(41), 2799-2805 (2007)

6. Deutsches Zentrum für Diabetesforschung. Diabetes: Zahlen (2012). http://www.dzd-ev.de/diabetes-die-krankheit/zahlen/index .html Accessed $21 \mathrm{Feb}$ (2018)

7. Alberti, K., Zimmet, P.: Definition, diagnosis and classification of diabetes mellitus and its complications. Part 1: diagnosis and classification of diabetes mellitus. Provisional report of a WHO consultation. Diabet. Med. 15(7), 539-553 (1998)

8. Icks, A., Rathmann, W., Rosenbauer, J., Giani, G.: Gesundheitsberichterstattung des Bundes, Heft 24: Diabetes mellitus. Robert Koch-Institut (2007)
9. Pfeiffer, A.: Die verschiedenen Formen der Zuckerkrankheit und deren Genetik, Diabetologie kompakt. Grundlagen und Praxis. Stuttgart (2001):Springer-Verlag Berlin Heidelberg

10. Janka, H.: Prävalenz des Diabetes mellitus und der Folgekrankheiten. Diabetologie Informationen 4, 243-254 (1996)

11. Waldhäusl, W.K., Gries, F.A., Scherbaum, W.: Diabetes in der Praxis. Springer DE, Berlin (2004)

12. DiabetesDE, Deutscher Gesundheitsbericht Diabetes 2013. Deutsche Diabetes-Hilfe, Berlin (2013)

13. Nagel, H., Baehring, T., Scherbaum, W.A.: DiabetesversorgungDeutliche regionale Unterschiede. Dtsch. Arztebl. 103(7), 390399 (2006)

14. Mühlbacher, A.C.: Patient-centric HTA: different strokes for different folks. Expert review of pharmacoeconomics \& outcomes research 15(4), 591-597 (2015)

15. Townson, J.K., Gregory, J.W., Cohen, D., et al.: Delivering early care in diabetes evaluation (DECIDE): a protocol for a randomised controlled trial to assess hospital versus home management at diagnosis in childhood diabetes. BMC Pediatr. 11(1), 7 (2011)

16. Martin, S., Schneider, B., Heinemann, L., et al.: Self-monitoring of blood glucose in type 2 diabetes and long-term outcome: an epidemiological cohort study. Diabetologia 49(2), 271-278 (2006)

17. Wright, A., Cull, C., Holman, R., et al.: United Kingdom Prospective Diabetes Study 24: a 6-year, randomized, controlled trial comparing sulfonylurea, insulin, and metformin therapy in patients with newly diagnosed type 2 diabetes that could not be controlled with diet therapy. Ann. Intern. Med. 128(3), 165-175 (1998)

18. Martin, S., Landgraf, R.: Systematic analysis of diabetic patient care in Germany. Dtsch. Med. Wochenschr. 130, 1078-1084 (2005)

19. Barnard, K., Parkin, C., Young, A., Ashraf, M.: Use of an automated bolus calculator reduces fear of hypoglycemia and improves confidence in dosage accuracy in patients with type 1 diabetes mellitus treated with multiple daily insulin injections. J. Diabetes Sci. Technol. 6(1), 144-149 (2012)

20. Klonoff, D.C.: Personalized medicine for diabetes. J. Diabetes Sci. Technol. (Online) 2(3), 335 (2008)

21. Weissmann, J., et al.: Improving process quality and medical outcome of diabetes treatment with information management: the physician's perspective. Results from the Multicenter Observational VISION Study. In: Poster Presentations at Advanced Technologies and Treatments for Diabetes (ATTD) 5th International Conference, Barcelona, Spain 8-11, (2012)

22. Brotons, C.E.A.: Benefits of a blood glucose data reader device in the management of type 2 diabetes mellitus: primary care nurses perspective. In: Poster Presentations at Advanced Technologies and Treatments for Diabetes (ATTD) 5th International Conference. Barcelona, Spain (2012)

23. Lancaster, K.J.: A new approach to consumer theory. J. Polit. Econ. 74(2), 132-157 (1966)

24. McFadden, D.: Conditional logit analysis of qualitative choice behavior. Zarembka 1974, 105-142 (1974)

25. Ben-Akiva, M.E., Lerman, S.R.: Discrete Choice Analysis: Theory and Application to Travel Demand. MIT Press Series in Transportation Studies. MIT Press, Cambridge [u.a.] (1985)

26. Hensher, D.A., Rose, J.M., Greene, W.H.: Applied Choice Analysis: A Primer. Cambridge University Press, Cambridge [u.a.] (2005)

27. Johnson, F.R.: Why not ask?: measuring patient preferences for healthcare decision making. Patient Patient Centered Outcomes Res. 1(4), 245-248 (2008)

28. Lancsar, E., Louviere, J.: Conducting discrete choice experiments to inform healthcare decision making: a user's guide. PharmacoEconomics 26(8), 661-678 (2008) 
29. Ryan, M., Gerard, K., Amaya-Amaya, M.: Using discrete choice experiments to value health and health care. The economics of non-market goods and resources (Vol. 11). Springer Science \& Business Media, Dordrecht

30. Bridges, J., Hauber, A., Marshall, D., et al.: Checklist for conjoint analysis applications in health: report of the ISPOR conjoint analysis good research practices taskforce 14(4):403-413 (2009)

31. Mühlbacher, A., Bethge, S., Tockhorn, A.: Präferenzmessung im Gesundheitswesen: Grundlagen von Discrete-Choice-Experimenten. Gesundheitsökonomie \& Qualitätsmanagement 18(4), 159-172 (2013)

32. Mühlbacher, A., Johnson, F.R.: Choice experiments to quantify preferences for health and healthcare: state of the practice. Appl. Health Econ. Health Policy 14(3), 253-266 (2016)

33. Bridges, J.F., Kinter, E.T., Kidane, L., et al.: Things are looking up since we started listening to patients: trends in the application of conjoint analysis in health 1982-2007. Patient Patient Centered Outcomes Res. 14(4), 273-282 (2008)

34. Louviere, J.J., Hensher, D.A., Swait, J.D.: Stated Choice Methods: Analysis and Application. Cambridge University Press, Cambridge [u.a.] (2000)

35. Telser, H.: Nutzenmessung im Gesundheitswesen: Die Methode der Discrete-Choice-Experimente (ed.) Forschungsergebnisse, S.v., vol. 78. Kovac, Hamburg (2002)

36. Orme, B.: Getting Started with Conjoint Analysis. Research Publishers LLC., Madison (2005)

37. Yang, J.-C., Johnson, F.R., Kilambi, V., Mohamed, A.F.: Sample size and utility-difference precision in discrete-choice experiments: a meta-simulation approach. J. Choice Model. 16, 50-57 (2015)

38. ChoiceMetrics: NGene. http://www.choice-metrics.com Accessed 15 April (2018)

39. Rabe-Hesketh, S., Skrondal, A., Pickles, A.: GLLAMM manual. Division of Biostatistics Working Paper Series, U.C. Berkeley (2004)

40. Bryan, S., Gold, L., Sheldon, R., Buxton, M.: Preference measurement using conjoint methods: an empirical investigation of reliability. Health Econ. 9(5), 385-395 (2000)

41. Mas-Colell, A., Whinston, M.D., Green, J.R.: Microeconomic Theory, vol. 1. Oxford University Press, New York (1995)

42. Marshall, D.A., Johnson, F.R., Phillips, K.A., et al.: Measuring patient preferences for colorectal cancer screening using a choiceformat survey. Value Health 10(5), 415-430 (2007)

43. Tamayo, T., Brinks, R., Hoyer, A., Kuß, O., Rathmann, W. Prävalenz und Inzidenz von Diabetes mellitus in Deutschland. Robert Koch-Institut, 2016, Epidemiologie und Gesundheitsberichterstattung. 113

44. Aristides, M., Weston, A.R., FitzGerald, P., et al.: Patient preference and willingness-to-pay for Humalog Mix 25 relative to Humulin 30/70: a multicountry application of a discrete choice experiment. Value Health 7(4), 442-454 (2004)

45. Guimaraes, C., Marra, C.A., Colley, L., et al.: A valuation of patients' willingness-to-pay for insulin delivery in diabetes. Int. J. Technol. Assess. Health Care 25(3), 359-366 (2009)

46. Guimarães, C., Marra, C.A., Gill, S., et al.: A discrete choice experiment evaluation of patients' preferences for different risk, benefit, and delivery attributes of insulin therapy for diabetes management. Patient Prefer. Adherence 4, 433 (2010)

47. Mühlbacher, A., Bethge, S.: What matters in type 2 diabetes mellitus oral treatment? A discrete choice experiment to evaluate patient preferences. Eur. J. Health Econ. 17(9), 1125-1140 (2016)

48. Haffner, S.M., Lehto, S., Rönnemaa, T., et al.: Mortality from coronary heart disease in subjects with type 2 diabetes and in nondiabetic subjects with and without prior myocardial infarction. N. Engl. J. Med. 339(4), 229-234 (1998)
49. Khunti, K., Davies, M., Majeed, A., et al.: Hypoglycemia and risk of cardiovascular disease and all-cause mortality in insulin-treated people with type 1 and type 2 diabetes: a cohort study. Diabetes Care 38(2), 316-322 (2015)

50. Hauber, A.B., Mohamed, A.F., Johnson, F.R., Falvey, H.: Treatment preferences and medication adherence of people with type 2 diabetes using oral glucose-lowering agents. Diabet. Med. 26(4), 416-424 (2009)

51. Polster, M., Zanutto, E., McDonald, S., et al.: A comparison of preferences for two GLP-1 products-liraglutide and exenatide-for the treatment of type 2 diabetes. J. Med. Econ. 13(4), 655-661 (2010)

52. Bøgelund, M., Vilsbøll, T., Faber, J., et al.: Patient preferences for diabetes management among people with type 2 diabetes in Denmark-a discrete choice experiment. Curr. Med. Res. Opin. 27(11), 2175-2183 (2011)

53. Hauber, A.B., Han, S., Yang, J.-C., et al.: Effect of pill burden on dosing preferences, willingness to pay, and likely adherence among patients with type 2 diabetes. Patient Prefer. Adherence 18(7), 937-949 (2013)

54. Bundesärztekammer, Bundesvereinigung, K.: Arbeitsgemeinschaft der Wissenschaftlichen Medizinischen Fachgesellschaften, et al. (eds.) Nationale Versorgungsleitlinie: Therapie des Typ-2-Diabetes. Kurzfassung. Berlin (2013)

55. Gelhorn, H., Stringer, S., Brooks, A., et al.: Preferences for medication attributes among patients with type 2 diabetes mellitus in the UK. Diabetes Obes. Metab. 15(9), 802-809 (2013)

56. Whitmer, R.A., Karter, A.J., Yaffe, K., et al.: Hypoglycemic episodes and risk of dementia in older patients with type 2 diabetes mellitus. JAMA 301(15), 1565-1572 (2009)

57. Byun, J.-H., Kwon, S.-H., Lee, J.-E., et al.: Comparison of benefit-risk preferences of patients and physicians regarding cyclooxygenase- 2 inhibitors using discrete choice experiments. Patient Prefer. Adherence 10, 641 (2016)

58. Eliasson, L., Bewley, A.P., Mughal, F., et al.: Evaluation of psoriasis patients' attitudes toward benefit-risk and therapeutic tradeoffs in their choice of treatments. Patient Prefer. Adherence 11, 353 (2017)

59. Copsey, B., Buchanan, J., Fitzpatrick, R., et al.: Duration of treatment effect should be considered in the design and interpretation of clinical trials: Results of a discrete choice experiment. Med. Decis. Mak. 39(4), 461-473 (2019)

60. Harrison, M., Rigby, D., Vass, C., et al.: Risk as an attribute in discrete choice experiments: a systematic review of the literature. Patient Patient Centered Outcomes Res. 7(2), 151-170 (2014)

61. Kløjgaard, M.E., Bech, M., Søgaard, R.: Designing a stated choice experiment: the value of a qualitative process. J. Choice Model. 5(2), 1-18 (2012)

62. Blinman, P., Alam, M., Duric, V., et al.: Patients' preferences for chemotherapy in non-small-cell lung cancer: a systematic review. Lung Cancer 69(2), 141-147 (2010)

63. Manthey, L.: Methoden der Präferenzmessung. Grundlagen, Konzepte und experimentelle Untersuchungen, p. VIII, 212 S. Universität Jena, Norderstedt (2007)

64. Helm, R., Steiner, M.: Präferenzmessung: Methodengestützte Entwicklung zielgruppenspezifischer Produktinnovationen. W. Kohlhammer Verlag, Stuttgart (2008)

65. Zylka-Menhorn, V.: Amerikanischer Diabetes Kongress (1): Wenn man des Guten zu viel tut. Dtsch Arztebl 114(31-32), A-1482/B1251/C-1225 (2017)

66. Mühlbacher, A., Bethge, S., Ekert, S., et al.: Der Wert von Innovationen im Gesundheitswesen: Spielen die Patientenpräferenzen eine Rolle? 14(2), 53-62 (2008)

Publisher's Note Springer Nature remains neutral with regard to jurisdictional claims in published maps and institutional affiliations. 


\section{Authors and Affiliations}

\section{Axel C. Mühlbacher ${ }^{1,2,3}$ (D) Andrew Sadler ${ }^{1} \cdot$ Christin Juhnke $^{1}$}

1 Gesundheitsökonomie und Medizinmanagement, Hochschule Neubrandenburg, Brodaer Straße 2, 17033 Neubrandenburg, Germany

2 Gesellschaft Für Empirische Beratung GmbH (GEB), Freiburg, Germany
3 Department of Population Health Sciences, Duke University, Durham, NC, USA 